\title{
DESIGNING FOR BETTER HEALTHCARE: A SYSTEMIC APPROACH UTILISING BEHAVIOURAL THEORY, TECHNOLOGY AND AN UNDERSTANDING OF HEALTHCARE DELIVERY SYSTEMS
}

\author{
Ciccone, Nicholas W; Patou, François; Maier, Anja M \\ DTU - Technical University of Denmark
}

\begin{abstract}
An ageing population leading to more chronic disease is straining healthcare systems. This paper makes two core contributions to healthcare systems design research: Firstly, a systemic techno-behavioural approach is presented to support intervention design with value-effective health outcomes. The systemic techno-behavioural perspective takes into consideration the interaction between three angles: The current healthcare system in place, the technological opportunities for addressing an issue and a broader and deeper understanding of the behaviour of those involved. The purpose of considering these three angels is to create interventions that are more robust. This will help inform healthcare systems design researchers and other stakeholders. Secondly, it is proposed that interventions should be grounded in behavioural theory, a collection of theories are presented to be incorporated in the design process of interventions. The systemic techno-behavioural approach is applied to dementia care highlighting the need to understand the dynamic relationship between the context of the current healthcare delivery system, technology, and behaviour to improve quality of care during the progression of the disease.
\end{abstract}

Keywords: Healthcare design, Large-scale engineering systems, Human behaviour in design, Dementia, Systems Engineering (SE)

\section{Contact:}

Ciccone, Nicholas William

Danish Technical University (DTU)

Management Engineering

Denmark

nicic@dtu.dk

Cite this article: Ciccone, N.W., Patou, F., Maier, A.M. (2019) 'Designing for Better Healthcare: A Systemic Approach Utilising Behavioural Theory, Technology and an Understanding of Healthcare Delivery Systems', in Proceedings of the 22nd International Conference on Engineering Design (ICED19), Delft, The Netherlands, 5-8 August 2019. DOI: $10.1017 /$ dsi.2019.98 


\section{INTRODUCTION}

As people age, they become more susceptible to develop chronic conditions and as such, the resources required to deal with their medical needs increase (Denton, \& Spencer, 2010). Currently, Europe has an ageing population with the total population percentage of people over 65 rising from $9.8 \%$ in 1960 to $19.8 \%$ in 2017. This trend is set to continue with median ages predicted to rise from 41.6 years in 2015 to 47.8 in 2100 (United Nations Population Division, 2017). The result of an increase in an ageing population with greater access to healthcare is a higher cost on economies with higher GDP spending being needed to maintain care (WHO European Health Information Gateway, 2018). This demographic shift is straining current healthcare systems which have limited budgets and are failing to adapt rapidly enough (Locock, 2003; Rouse \& Serban, 2014). It has been shown that interventions that aim to improve health behaviour reduce mortality at a low cost or at a cost saving with many preventable causes of death (Cohen, Neumann \& Weinstein, 2008). As such, it is argued here that a better understanding of human behaviour and technology helps us to create more robust interventions that could curb the current difficulties by being more value-effective.

Value-effectiveness in healthcare guided by an engineering systems design perspective has previously been proposed (Patou \& Maier, 2017). Systems design research examines interactions amongst the components of complex sociotechnical systems (Harrison, Henriksen \& Hughes, 2007; Clarkson et al., 2004). Patou \& Maier's (2017) review depicts the current state of technology-development trends in healthcare; those that should ideally lead us to more Predictive, Preventative, Personalised and Participative healthcare and medicine: P4 Healthcare (Flores et al., 2013). Patou \& Maier identified several key technology trends: Decentralisation, personalisation, connectivity, pervasiveness, and stratification. It is argued that an engineering systems design perspective is essential for new technologybased care models to deliver on their expectations. More specifically, the transformation of national healthcare systems can partly be addressed through bottom-up engineering of products and services that will be integrated into and contribute to the value-effectiveness of the overall healthcare system.

The macro-trends of technology in healthcare identified are purely descriptive (Patou, \& Maier, 2017). The Engineering Systems Group at DTU - Technical University of Denmark also sees a need for a prescriptive framework which adds empirical robustness to the design process when designing/redesigning value effective healthcare delivery. As such, this position paper proposes three entry angles that could be considered together for any healthcare improvement and newly designed initiative. These angles were selected on calls previously made to advance the design of interventions, using theories and models that are as precise, quantitative, and as testable as possible (Hekler et al., 2016). We believe this can be achieved through three channels: 1) A broader and deeper understanding of the behaviour of those involved using established behavioural theories. 2) Improved data collection and analysis by using technological opportunities and trends. 3) The consideration of the current healthcare system and its stakeholders (Figure 1).

This paper makes two core contributions to healthcare systems design research and healthcare service improvement: Firstly, when (re-)designing healthcare interventions, it proposes a need for simultaneous consideration of human behaviour, technology, and the context of the current healthcare delivery system and its stakeholders e.g. the patient, caregiver or policy maker (Figure 1). Secondly, it provides an overview of behavioural theories introduced to healthcare intervention design mainly from behavioural sciences. This has important implications for healthcare system design researchers, medical practitioners and policy makers who are looking for informed theory-based approaches to improve interventions relating to healthcare improvement. 


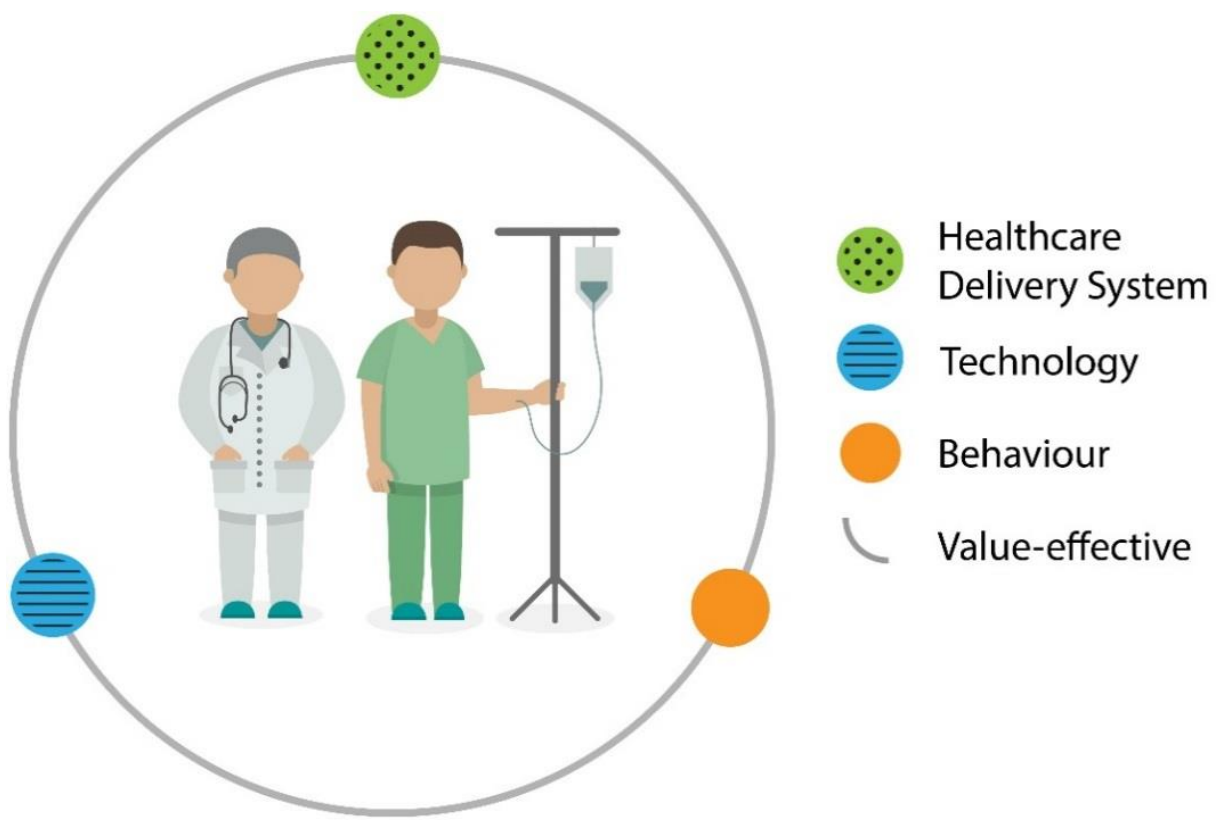

Figure 1: A techno-behavioural approach to healthcare system design.

The remainder of this paper is structured as follows: Section 2 explores each component part of the approach, in Section 3 the systemic techno-behavioural approach is exemplified by looking at dementia care and concluding in Section 4, implications for healthcare research, practice, and policy making are discussed.

\section{A SYSTEMIC TECHNO-BEHAVIOURAL FOCUS}

\subsection{Behavioural understanding}

There is a growing body of evidence that behaviour is fundamental to morbidity and mortality (Pitts, 2003). Behaviour can provide rich data to inform new innovations in healthcare system design, while also being modifiable. Health behaviour theories and models can be used for a variety of purposes: For understanding the determinants of health behaviours (behaviour driven), for identifying channels to change them (behaviour changing), and allowing for easier translation from theory to practice (De Vries, 2017). Developing this understanding is beneficial when designing new healthcare delivery systems dealing with health related issues. Behavioural understanding relates to any stakeholder, including patients and health care professionals. Choosing which theories should inform design can be confusing as over 1700 constructs have been identified within 83 health behaviour theories (Michie et al., 2014). Some of these theories have overlapping constructs (Noar \& Zimmerman, 2005) that can be operationalised separately (Johnston et al., 2014). Recently, attempts have been made to combine theories (De Vries, 2017) but these are still in their infancy.

This paper offers a review of some of the most cited health behaviour theories, illustrated in Figure 2 . Biomedical theories of health behaviour focus on purely biological indicators to identify and change a behaviour/condition. Behaviourism (behavioural learning theories) operate on the principle of stimulus-response, whereby all behaviour is caused by external stimuli. The Communication approach prescribes it is the availability and presentation of information that affects behaviour. Cognitive theories focus on mental processes and what internal and external factors influence behaviour. Ecological models are holistic, proposing that behaviour has multiple levels of influence including: intrapersonal (biological, psychological), interpersonal (social, cultural), organisational, community, physical environmental, and policy. Integrated theories contain elements from different schools of psychology to interpret behaviour. Figure 2 presents a collection of the most widely cited health behaviour theories. The collection is intended to inform the design and implementation of healthcare interventions. The United Kingdom Medical Research Council has recognised the importance of complex interventions informed by behavioural theory and has detailed guidance about how to utilise them (Lakshman et al., 2014) This notion has also been followed in a number of papers that introduce their own approach (Campbell et al., 2000; Craig et al., 2006; ICEBeRG, 2006). Fogg (2009) focuses 
on behaviours which are entwined with a technology to launch the intervention, whereby pervasive technologies are typically intended to support motivation or ability as well as providing an active trigger for behaviour.

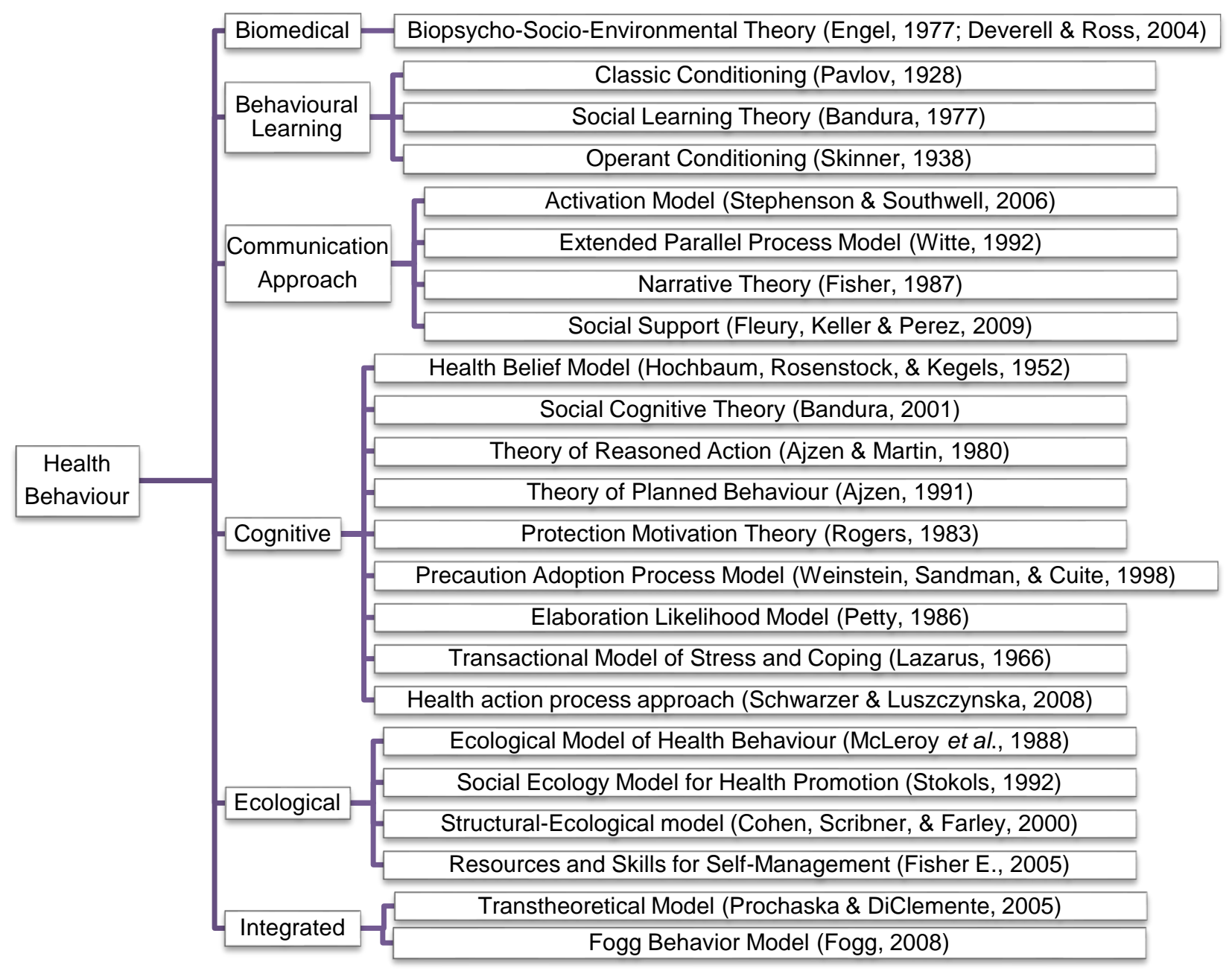

Figure 2: A taxonomy of frequently cited health behaviour theories to inform healthcare intervention design.

Improvements in the design of current healthcare interventions can be facilitated at the patient, caregiver, organisation or policy level (Patou \& Maier 2017). An important application area in designing bottom- up informed healthcare systems is behavioural understanding at the level of the healthcare professional. 'Clinical behaviours are an important proximal determinant of quality of care' (Ferlie \& Shortell, 2001). Using psychological theory to promote the uptake of research findings and to change the behaviour of healthcare professionals has the potential to vastly improve care (Eccles et al., 2005). Human behaviour influenced by nudge and persuasion through design are increasingly important topics in design research. Theoretical approaches are slow to adopt behaviour change operationalised in the design process. When considering design for behaviour change a new perspective is needed on the traditional design process, integrating key insights from behaviour change theory. Using this foundation a behavioural design process has previously been explored by Cash, Hartlev \& Durazo (2017). However, so far, this focuses on unconscious behaviour change strategies and does so far not encompass technology.

A myriad of other factors impact health behaviour which fall outside of the scope of most traditional behavioural theories. Education, cultural awareness, social support programs, and public policies can have great impact on the evolution of attitudes, perceptions, knowledge, and practices that foster improved health. These fall in the realm of ecological theories; a perspective that should not be overlooked when considering the complexity of socio-technical systems. These theories have particular gravitas when applied to patients whose health fall outside their control, or fall at the organisation level. An example of this is the availability of medicine or diagnostic technologies 
(Sumartojo, 1993; Farmer, 1997). Having this understanding leads to more encompassing models (Stokols, 1992; Cohen, Scribner, \& Farley, 2000). A review which analysed 193 empirical research articles (Painter et al., 2008) determined theory-based health behaviour change programs are more effective than those that do not use theory. The articles were collected from public health, medicine, and psychology journals and found that the use of theory led to more effective interventions and should be continued to be used to move the field forward. Theory-based interventions are more effective as they allow for understanding of the target and causal determinants of behaviour and behaviour change, which in turn allows for theoretical mechanisms of change to be developed, they can have their validity and reliability tested as they are based on identifiable and objective frameworks and finally, they allow for theory development which can be applied to different contexts, demographics and behaviours (Michie et al., 2008).

\subsection{Technology}

Continuous technological developments in healthcare are considerably improving both patient quality of life and lifespan (Cutler \& McClellan, 2001). Not only has technology changed the experience of ill health for the patient and their relatives, but it has also had a radical impact on medical processes and driven change in healthcare professional practices (Hofmann, 2015). Most noteably using smart and personal technologies for health purposes. This may include physical sensors to collect data from a patient and their surroundings (Meixner \& Jones, 2008), computational capacity to store and analyse this data, and often providing a platform to deliver personalised actionable outcomes based on the collected data. Smart health technologies illustrate the combinatorial advantages of Connectivity, Pervasiveness and Decentralisation (Patou, \& Maier, 2017). These technologies rely heavily on physiological and behaviour measures of an individual (Free et al., 2013). However technological advancement is not enough to improve health alone and does present certain barriers: the cost of innovation burdens healthcare systems, with half of the increase in the overall costs in healthcare being attributed to technology (Sorenson, Drummond \& Bhuiyan Khan, 2013). New technology raises the profile of a hospital or other healthcare institution and can cause an 'arms race' requiring considerable resources and specialist training (Carrier, Dowling \& Berenson, 2013). This also carries the risk of over-diagnosis, an example of which is when people without symptoms are diagnosed with a disease that ultimately will not cause them to experience symptoms or early death (Moynihan, Doust \& Henry, 2012). Despite this, there appears to be a consensus that technology based solutions if implemented effectively will deliver a value-effective solution (Cutler \& McClellan, 2001),

\subsection{Context of current healthcare delivery systems}

Health care delivery systems are complex socio-technical systems defined by dynamic networks with internal system components (people, technologies, physicality's, care processes, and organisation) and environmental influences (technology trends, markets/economies, regulations/policy, and consumers). Healthcare systems are still primarily tailored around a conventional centralised, reactive, episodic and population-based care delivery model (Hood, Balling, \& Auffray, 2012). Healthcare interventions often have to be tailored to the system in which they will be applied. Healthcare policy makers and care providers have started to realise that many obstacles such as process inefficiencies, budget limitations, increasing technology-adoption costs, and scarcity of care personnel (Cutler, Rosen, \& Vijan, 2006; Spillman \& Lubitz, 2000) could not be overcome without first acknowledging the complexity of the problem (Rouse \& Serban, 2014). Systems design research is able to evaluate these systems by examining the interactions among sub-components and their possible impact on quality and cost. The scientific and technological disruptions of the past two decades are driving a paradigmshift, with a trajectory set towards being more patient-centric (Hood \& Auffray, 2013) or rather, more human-centric - one of the main premises of a systemic techno-behavioural approach.

\section{APPLYING A TECHNO-BEHAVIOURAL APPROACH TO DEMENTIA}

In order to design a robust health intervention the interaction between the healthcare delivery system, technological opportunity, and behaviour theory relevant to a particular health issue and its healthcare delivery service need to be understood (see figure 3a). Dementia is one of the most prevalent chronic conditions afflicting aging populations globally (Ferri, 2005). Cognitive decline is often seen as part of the normal ageing process and sometimes cognitive decline develops into mild cognitive impairment 
or potentially dementia, whereby an individual loses their ability to function independently. This puts strain on systems already suffering from process inefficiencies, budget limitations, increasing technology-adoption costs, and scarcity of care personnel (Cutler, Rosen, \& Vijan, 2006). The best stages for preventative treatment to slow the progression of a disease are often missed due to the slow and often unnoticed progression of the disease (Bachman et al., 1993). As dementia understanding and research continues to grow there have been many interventions that incorporate macro technology trends launched to facilitate better health of those affected (Flores et al., 2013; Patou \& Maier, 2017).

a)

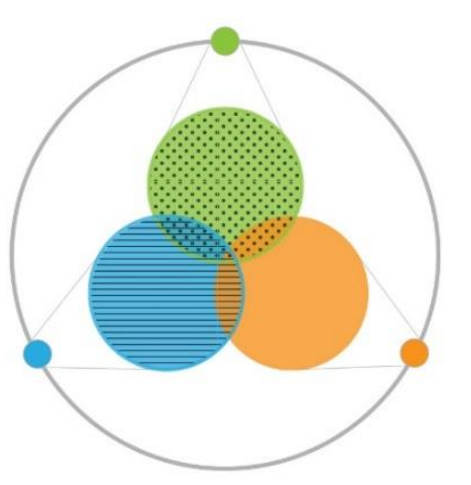

b)

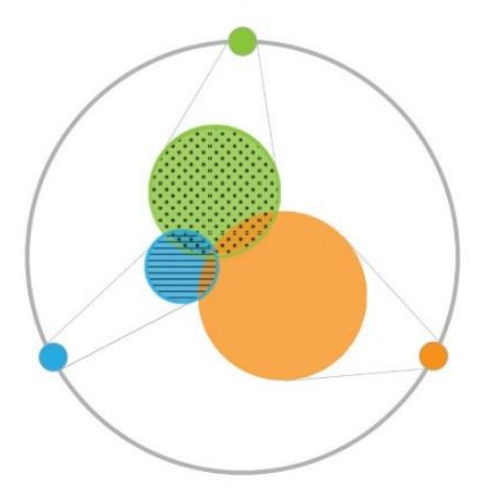

c)

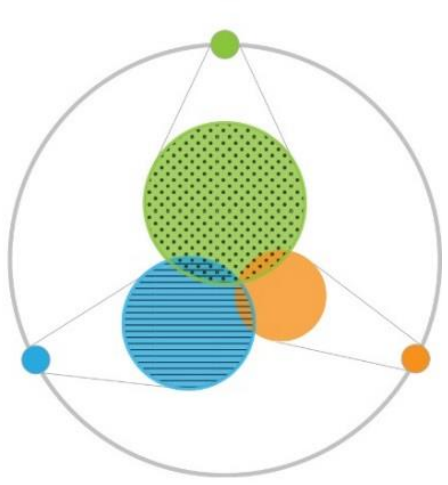

Healthcare Delivery System

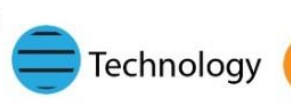
Behaviour Value-effective

\section{Figure 3: a) Techno-behavioural interactions b) Behaviour change interventions c) Behaviour} driven interventions.

Non-pharmacological interventions aimed at slowing down the progression of cognitive decline can be broadly placed into two groups: Behaviour change interventions that aim to either alter behaviours that are risk factors associated with cognitive impairment / change the behaviour of the caregiver, or behaviour driven solutions that utilise smart technologies to collect behavioural data from patients and then intervene accordingly. Depending at what stage of disease development the intervention falls, affects which aspect of the approach will be utilised more predominantly, hence the difference in figure $3 \mathrm{~b}$ and $3 \mathrm{c}$. Behavioural change theories (see figure 2) provide a psychological framework when designing interventions to change health behaviours. They enable understanding of structural and psychological determinants of behaviours (Michie et al., 2008; Painter et al., 2008). Health behaviour change models have been effectively used to design interventions relating to dementia risk behaviours. These include the attitudes and beliefs of a population surrounding health and lifestyle. While dementia is generally deemed not to be preventable, prevention strategies are related to limiting disease progression and reducing negative consequences of symptoms. A meta-analysis of nonpharmacological interventions for the neuropsychiatric symptoms of dementia found them to be effective in reducing behavioural and psychological symptoms of the patient and reducing caregiver distress (Brodaty \& Arasaratnam, 2012).

The Health Belief Model (HBM) has been used as a conceptual framework to measure the motivations behind behaviour and lifestyle changes associated with dementia risk (Kim et al., 2014). It is one of the most cited theories relating to health-related behaviours and health promotion (Guvenc, Akyuz \& Açikel, 2011; Glanz, Rimer \& Viswanath, 2008). Identifying beliefs and motivations relating to health behaviours can inform the development of interventions designed to increase desirable health outcomes (Champion, 1984). Positive health-promoting behaviour change is more prone to occur when there is a high threat level to an individual within their current behavioural patterns. This perceived belief of susceptibility and severity of a behaviour is weighed against the value of the outcome of the behavioural change and if the perceived benefits outweigh perceived barriers. According to the HBM both internal or external stimuli (action cues), desire to achieve an outcome (motivation), and confidence in one's ability to perform the desired behaviours (self-efficacy) are needed (Glanz, Rimer \& Viswanath, 2008). Using the underpinning of the HBM a new scale was developed the MCLHB-DRR (Kim et al., 2014). This was in an effort to understand beliefs and motivations of behaviours relating to dementia in those at risk of developing it. This model incorporated dimensions of the HBM (perceived susceptibility, perceived severity, perceived 
benefits, perceived barriers, cues to action, general health motivation, and self-efficacy) on lifestyle and health behaviours relating dementia risk reduction. The intention was for it to be used in the development and evaluation of dementia prevention interventions. Fear of developing dementia was found to be a major motivating factor to initiate health and lifestyle behavioural change. A notion underpinned by another behavioural theory, the Extended Parallel Process Model (EPPM) (Witte, 1992). This proposes that effective risk messages are grounded in fear appeals and scare tactics. The EPPM explains the conditions under which fear appeals are likely to succeed and could be used in combination with the HBM to promote greater levels of preventative behaviour to reduce cognitive decline in the future. Three large cognitive impairment prevention studies in Europe based on behavioural theory have been implemented: the Prevention of Dementia by Intensive Vascular Care (PreDIVA) study; the Finnish Geriatric Intervention Study to Prevent Cognitive Impairment and Disability (FINGER), and the Multi-domain Alzheimer Preventive Trial (MAPT; Richard et al., 2009). These interventions rely heavily on behaviour change to inform their method of action (see figure $3 \mathrm{~b}$ ).

Although these behavioural change interventions help identify and reduce dementia development, they fail to pose a solution for patients that develop the condition.

Behaviour driven systems can help alleviate the social, economic and medical burdens of living with cognitive impairment. Most current design processes focus on realising technologically facilitated behaviour change whereby technology is implemented to actively drive the interaction between the user and the behavioural intervention (Kelders et al., 2012). These interventions are often centred on utilising smart health technologies to improve healthcare through data collection, processing and application. This shift in resource requirements can be seen in figure $3 \mathrm{c}$ with greater weight being placed on the healthcare delivery system and technology. A number of studies support the effectiveness of these systems both in a hospital and at home (Baig \& Gholamhosseini, 2013). Thorpe, Forchhammer \& Maier (2017) exemplified how integrating sensor-driven information about user behaviour can support the healthcare design goals of personalisation, adaptability and scalability, while emphasising patient quality of life. Lin \& colleagues (2006) integrated radio frequency identification, global positioning system, mobile communications, and geographic information system (GIS) to construct a stray prevention system for elderly suffering from dementia. In order to make an effective intervention the most suitable technology was used to collect data about the behaviours of the patient. The information collected was then integrated into a system. This ultimately resulted in a patient receiving better quality of care. A similar study used information technology to enhance the professional judgment of caregivers, strengthen internal safety monitoring at care organisations, and improve the quality of patients by using radio frequency identification (RFID) technology (Lin et al., 2008). Both these interventions realise that dementia care requires similar levels of knowledge in behaviour technology and systems. Following this study, recommendations to improve the quality of the physiological data were made to include a theoretical framework combined with experimental procedures at the initial stages of intervention development (Baig \& Gholamhosseini, 2013).

\section{DISCUSSION AND CONCLUDING MESSAGE}

An aging population is straining traditional healthcare systems. A systemic techno-behavioural approach has been proposed following macro-trends of technology in healthcare (Patou, \& Maier, 2017). The Techno-behavioural perspective takes into consideration three overarching angles: The current healthcare system in place, the technological opportunities for addressing a particular issue and trends that can be utilised and a more broad and deep understanding of the behaviour of those involved (both behaviour driven and change). The purpose of considering these three angels is to create more robust interventions that recognise the interactions between behaviour and technology to help inform healthcare systems design researchers, healthcare practitioners and policy makers. This is based on a bottom up approach to engineering system design involving the relationship of patient/caregiver behaviour and technology integrated into the current healthcare delivery system to drive innovation and improvement. This highlights the complexity of current healthcare systems and the need for a system understanding in order to design effective interventions. A proposition is made that interventions should be grounded in behavioural theory. A collection of such theories has been presented that may form the basis for designing interventions and healthcare solutions. The utility of technology and its interaction with behaviour, paired with a humancentred (bottom-up) approach, has been demonstrated to improve quality of care in some existing interventions (Lakshman et al., 2014; Eccles et al., 2005). The application of the systemic technobehavioural approach proposed here has then been incorporated into dementia care, giving several 
examples of ongoing efforts improving the effectiveness of interventions targeting cognitive decline. For example, using The Health Belief Model (HBM) as a conceptual framework along with the Extended Parallel Process Model (EPPM) to promote greater levels of preventative behaviour to reduce cognitive decline in the future. These interventions are often centred on utilising smart health technologies to improve healthcare system through behaviour data collection, processing and application. Technological innovation has changed the experience of ill health for the patient and their relatives, but it has also had a radical impact on medical process and driving change in healthcare professional practices. This highlights the need for system design to be underpinned by robust behavioural theory and technology when creating interventions for a value effective outcome, not just in dementia care but to balance this relationship to improve system effectiveness across the wider healthcare domain. This will resonate with healthcare system design researchers and policy makers who aim to improve and redesign healthcare systems using technology and empirically validated behavioural theories.

\section{REFERENCES}

Ajzen, I. (1991), “The theory of planned behavior", Organizational Behavior and Human Decision Processes. Vol. 50 No. 2, pp. 179-211.

Ajzen, I. and Martin, F. (1980), Understanding Attitudes and Predicting Social Behaviour. Prentice-Hall, Englewood Cliffs, NJ.

Bachman, D.L., Wolf, P.A., Linn, R.T., Knoefel, J.E., Cobb, J.L., Belanger, A.J. and D’Agostino, R.B. (1993), "Incidence of dementia and probable Alzheimer's disease in a general population: the Framingham Study", Neurology, Vol. 43 No. 3 Part 1, pp. 515-515.

Baig, M.M. and GholamHosseini, H. (2013, July), "Wireless remote patient monitoring in older adults." In 2013 35th Annual International Conference of the IEEE Engineering in Medicine and Biology Society (EMBC) (pp. 2429-2432). IEEE.

Bandura, A. (1977), Social learning theory. Prentice Hall, Englewood Cliffs, NJ.

Bandura, A. (2001), "Social cognitive theory, An agentive perspective", Annual Review of Psychology, Vol. 52, pp. 1-26.

Brodaty, H. and Arasaratnam, C. (2012), "Meta-analysis of nonpharmacological interventions for neuropsychiatric symptoms of dementia”, American Journal of Psychiatry, Vol. 169 No. 9, pp. 946-953.

Campbell, M., Fitzpatrick, R., Haines, A., Kinmonth, A.L., Sandercock, P., Spiegelhalter, D. and Tyrer, P. (2000), "Framework for design and evaluation of complex interventions to improve health", Bmj, Vol. 321 No. 7262, pp. 694-696.

Carrier, E.R., Dowling, M. and Berenson, R.A. (2012), "Hospitals' geographic expansion in quest of wellinsured patients: will the outcome be better care, more cost, or both?", Health Affairs, Vol. 31 No. 4, pp. 827-835.

Cash, P.J., Hartlev, C.G. and Durazo, C.B. (2017), "Behavioural design: A process for integrating behaviour change and design", Design Studies, Vol. 48, pp. 96-128.

Champion, V.L. (1984), "Instrument development for health belief model constructs", Advances in Nursing Science.

Clarkson, P.J., Buckle, P., Coleman, R., Stubbs, D., Ward, J., Jarrett, J. and Bound, J. (2004), “Design for patient safety: a review of the effectiveness of design in the UK health service", Journal of Engineering Design, Vol. 15 No. 2, pp. 123-140.

Cohen, D., Scribner, R. and Farley, T. (2000), “A Structural Model of Health Behavior: A Pragmatic Approach to Explain and Influence Health Behaviors at the Populations Level”, Preventive Medicine, Vol. 30, pp. $146-154$.

Craig, P., Dieppe, P., Macintyre, S., Michie, S., Nazareth, I. and Petticrew, M. (2008), "Developing and evaluating complex interventions: the new Medical Research Council guidance", Bmj, Vol. 337, p. a1655.

Cutler, D.M. and McClellan, M. (2001), "Is technological change in medicine worth it?", Health Affairs, Vol. 20 No. 5, pp. 11-29.

Cohen, J.T., Neumann, P.J. and Weinstein, M.C. (2008), "Does preventive care save money? Health economics and the presidential candidates", New England Journal of Medicine, Vol. 358 No. 7, pp. 661-663.

Cutler, D.M., Rosen, A.B. and Vijan, S. (2006), "The Value of Medical Spending in the United States, 19602000”, New England Journal of Medicine, Vol. 355 No. 9, pp. 920-927.

De Vries, H. (2017), "An integrated approach for understanding health behavior; the I-change model as an example”, Psychol Behav Sci Int J, Vol. 2 No. 2, pp. 10-19080.

Denton, F.T. and Spencer, B.G. (2010), "Chronic health conditions: changing prevalence in an aging population and some implications for the delivery of health care services", Canadian Journal on Aging/La Revue canadienne du vieillissement, Vol. 29 No. 1, pp. 11-21.

Deverell, A. and Ross, E. (2004), "Psychosocial approaches to health, illness and disability", A reader for health care professionals. Van Schaik Publishers, Pretoria. 
Eccles, M., Grimshaw, J., Walker, A., Johnston, M. and Pitts, N. (2005), "Changing the behavior of healthcare professionals: the use of theory in promoting the uptake of research findings", Journal of clinical epidemiology, Vol. 58 No. 2, pp. 107-112.

Engel, G.L. (1977), “The need for a new medical model: a challenge for biomedicine”, Science. Vol. 196 No. 4286, pp. 129-136.

Farmer P: (1997), "Social scientists and the new tuberculosis", Soc Sci Med, Vol. 44, pp. 347-358.

Ferlie, E.B. and Shortell, S.M. (2001), "Improving the quality of health care in the United Kingdom and the United States: a framework for change”, The Milbank Quarterly, Vol. 79 No. 2, pp. 281-315.

Ferri, C.P., Prince, M., Brayne, C., Brodaty, H., Fratiglioni, L., Ganguli, M. and Jorm, A. (2005), "Global prevalence of dementia: a Delphi consensus study", The lancet, Vol. 366 No. 9503, pp. 2112-2117.

Fisher, E. (2005), "Ecologic approaches to self management: The case of diabetes", American Journal of Public Health, Vol. 95 No. 9, pp. 1523-1535.

Fisher, W.R. (1987), Human communication as narrative. University of South Carolina Press, Columbia.

Fleury, J., Keller, C. and Perez, A. (2009), "Social support theoretical perspective", Geriatric Nursing (New York, N.Y.), Vol. 30 No. 2 Suppl, pp. 11-4.

Flores, M., Glusman, G., Brogaard, K., Price, N.D. and Hood, L. (2013), "P4 medicine: how systems medicine will transform the healthcare sector and society", Personalized Medicine, Vol. 10 No. 6, pp. 565-576.

Fogg, B.J. (2008), A behavior model for persuasive design. Proceedings of the 4th international Conference on Persuasive Technology (p. 40). ACM.

Fogg, B.J. (2009), Creating persuasive technologies: An eight-step design process. In Persuasive Technology. Fourth International Conference, PERSUASIVE 2009 (pp. 1e6). Claremont, CA, USA, CA, USA

Free, C., Phillips, G., Galli, L., Watson, L., Felix, L., Edwards, P. and Haines, A. (2013), "The effectiveness of mobile-health technology-based health behaviour change or disease management interventions for health care consumers: a systematic review", PLoS medicine, Vol. 10 No. 1, p. e1001362.

Glanz, K., Rimer, B.K. and Viswanath, K. (Eds.). (2008), Health behavior and health education: theory, research, and practice. John Wiley \& Sons.

Guvenc, G., Akyuz, A. and Açikel, C.H. (2011), "Health belief model scale for cervical cancer and Pap smear test: psychometric testing”, Journal of Advanced Nursing, Vol. 67 No. 2, pp. 428-437.

Harrison, M.I., Henriksen, K. and Hughes, R.G. (2007), "Improving the health care work environment: a sociotechnical systems approach", Joint Commission journal on Quality and Patient Safety, Vol. 33 No. 11, pp. 3-6.

Hekler, E.B., Michie, S., Pavel, M., Rivera, D.E., Collins, L.M., Jimison, H.B. and Spruijt-Metz, D. (2016), "Advancing models and theories for digital behavior change interventions", American Journal of Preventive Medicine, Vol. 51 No. 5, pp. 825-832.

Hochbaum, G., Rosenstock, I. and Kegels, S. (1952), "Health belief model”, United States Public Health Service.

Hofmann, B. (2015), “Too much technology”, British Medical Journal, Vol. 350, p. h705

Hood, L. and Auffray, C. (2013), "Participatory medicine: A driving force for revolutionizing healthcare", Genome Medicine, Vol. 5 No. 12, p. 110.

Hood, L., Balling, R. and Auffray, C. (2012), "Revolutionizing medicine in the 21 st century through systems approaches", Biotechnology Journal, Vol. 7 No. 8, pp. 992-1001.

Improved Clinical Effectiveness through Behavioural Research Group. (2006), "Designing theoreticallyinformed implementation interventions”, Implementation Science, Vol. 1 No. 1, p. 4.

Johnston M, Dixon D, Hart J, Glidewell L and Schröder C. et al. (2014), "Discriminant content validity: A quantitative methodology for assessing content of theory-based measures, with illustrative applications", Br J Health Psychol Vol. 19 No. 2, pp. 240-257.

Kelders, S.M., Kok, R.N., Ossebaard, H.C. and Van Gemert-Pijnen, J.E.W.C. (2012), "Persuasive system design does matter: A systematic review of adherence to web-based interventions", Journal of Medical Internet Research, Vol. 14 No. 6, p. e152.

Kim, S., Sargent-Cox, K., Cherbuin, N. and Anstey, K.J. (2014), "Development of the motivation to change lifestyle and health behaviours for dementia risk reduction scale", Dementia and Geriatric Cognitive Disorders Extra, Vol. 4 No. 2, pp. 172-183.

Lakshman, R., Griffin, S., Hardeman, W., Schiff, A., Kinmonth, A.L. and Ong, K.K. (2014), "Using the Medical Research Council framework for the development and evaluation of complex interventions in a theorybased infant feeding intervention to prevent childhood obesity: the baby milk intervention and trial", Journal of Obesity, Vol. 2014.

Lazarus, R.S. (1966), Psychological Stress and the Coping Process. McGraw-Hill, New York.

Lin, C.C., Chiu, M.J., Hsiao, C.C., Lee, R.G. and Tsai, Y.S. (2006), "Wireless health care service system for elderly with dementia", IEEE Transactions on Information Technology in Biomedicine, Vol. 10 No. 4, pp. 696-704.

Locock, L. (2003), "Healthcare redesign: meaning, origins and application" BMJ Quality \& Safety, Vol. 12 No. 1, pp. 53-57. 
McLeroy, K.R., Bibeau, D., Steckler, A. and Glanz, K. (1988), “An Ecological Perspective on Health Promotion Programs", Health Education Quarterly, pp. 351-377.

Meixner, H. and Jones, R. (2008), Sensors, Micro-and Nanosensor Technology: Trends in Sensor Markets (Vol. 8). John Wiley \& Sons.

Michie S, West R, Campbell R, Brown J, Gainforth H (2014), ABC of behaviour change theories: Silverback Publishing.

Michie, S., Johnston, M., Francis, J., Hardeman, W. and Eccles, M. (2008), "From theory to intervention: mapping theoretically derived behavioural determinants to behaviour change techniques", Applied Psychology, Vol. 57 No. 4, pp. 660-680.

Moynihan, R., Doust, J. and Henry, D. (2015), "Preventing Overdiagnosis: how to stop harming the healthy", Preventing Overdiagnosis, Vol. 344, p. 47.

Noar, S.M., Zimmerman, R.S. (2005), "Health Behavior Theory and cumulative knowledge regarding health behaviors: are we moving in the right direction?", Health Educ Res Vol. 20 No. 3, pp. 275-290.

Painter, J.E., Borba, C.P., Hynes, M., Mays, D. and Glanz, K. (2008), "The use of theory in health behavior research from 2000 to 2005: a systematic review”, Annals of Behavioral Medicine, Vol. 35 No. 3, pp. 358362.

Patou, F. and Maier, A. (2017), Engineering value-effective healthcare solutions: A systems design perspective. In DS 87-3 Proceedings of the 21st International Conference on Engineering Design (ICED 17) Vol 3: Product, Services and Systems Design, Vancouver, Canada, 21-25.08. 2017 (pp. 031-040).

Pavlov, I. (1928), Conditioned reflexes: An investigation of the physiological activity of the cerebral cortex. Oxford University Press, London.

Petty. (1986), Communication and persuasion: central and peripheral routes to attitude change. SpringerVerlag, New York.

Pitts, M. (2003), The psychology of preventive health. Routledge.

Prochaska, J.O. and DiClemente, C.C. (2005), "The transtheoretical approach Handbook of psychotherapy integration". Oxford series in clinical psychology (2nd ed.). Oxford University Press, Oxford; New York.

Richard, E., Van den Heuvel, E., van Charante, E.P.M., Achthoven, L., Vermeulen, M., Bindels, P. J. and Van Gool, W.A. (2009), "Prevention of dementia by intensive vascular care (PreDIVA): a cluster-randomized trial in progress", Alzheimer Disease \& Associated Disorders, Vol. 23 No. 3, pp. 198-204.

Rogers, R.W. (1983), Cognitive and physiological processes in fear appeals and attitude change: A Revised theory of protection motivation. Guilford Press, New York.

Rouse, W.B. and Serban, N. (2014), "Understanding and managing the complexity of healthcare", Understanding and Managing the Complexity of Healthcare.

Rouse, W.B. and Serban, N. (2014), "Understanding and Managing the Complexity of Healthcare", Understanding and Managing the Complexity of Healthcare.

Schwarzer, R. and Luszczynska, A. (2008), "How to overcome health-compromising behaviors: The health action process approach", European Psychologist, Vol. 13 No. 2, pp. 141-151.

Skinner, B.F. (1938), The Behavior of organisms: An experimental analysis. Appleton-Century, New York.

Sorenson, C., Drummond, M. and Khan, B.B. (2013), "Medical technology as a key driver of rising health expenditure: disentangling the relationship", ClinicoEconomics and Outcomes Research: CEOR, Vol. 5, No. 223.

Spillman, B.C. and Lubitz, J. (2000), "The Effect of Longevity on Spending for Acute and Long-Term Care", New England Journal of Medicine, Vol. 342 No. 19, pp. 1409-1415.

Stephenson, M.T. and Southwell, B.G. (2006), "Sensation seeking, the activation model, and mass media health campaigns: Current findings and future direction for cancer communication. Journal of Communication, Vol. 56, pp. 38-56.

Stokols, D. (1992), "Establishing and Maintaining Healthy Environments: Toward a Social Ecology of Health Promotion", American Psychologist, Vol. 47, pp. 6-22.

Sumartojo, E. (1993), "When tuberculosis treatment fails", Am Rev Respir Dis, Vol. 147 No. 1311, p. e20.

Thorpe, J.R., Forchhammer, B.H. and Maier, A. (2017), Sensing behaviour in healthcare design. In DS 87-3 Proceedings of the 21st International Conference on Engineering Design (ICED 17) Vol 3: Product, Services and Systems Design, Vancouver, Canada, 21-25.08. 2017 (pp. 171-180).

United Nations, Department of Economic and Social Affairs, Population Division (2017), World Population Prospects: The 2017 Revision.

Weinstein, N.D., Sandman, P.M. and Cuite, C.L. (1998), "Experimental Evidence for Stages of Precaution Adoption", Health Psychology No. 17, pp. 445-453.

Witte, K. (1992), Putting the fear back into fear appeals: The extended parallel process model", Communication Monographs Vol. 59 No. 4, pp. 329-349.

World Health Organisation (2018) European Health Information Gateway: Total health expenditure as \% of GDP. Retrieved from https://gateway.euro.who.int/en/indicators/hfa_566-6711-total-health-expenditureas-of-gdp/visualizations/\#id=19661\&tab=notes 